\title{
Assessments of Environmental Awareness Among the Some Selective University Students of Bangladesh
}

\author{
Ahmad Kamruzzaman Majumder \\ Department of Environmental Science, Stamford University Bangladesh, Dhaka, Bangladesh \\ Email address: \\ kamrul_sub@hotmail.com \\ To cite this article: \\ Ahmad Kamruzzaman Majumder. Assessments of Environmental Awareness Among the Some Selective University Students of Bangladesh. \\ International Journal of Education, Culture and Society. Vol. 2, No. 6, 2017, pp. 190-194. doi: 10.11648/j.ijecs.20170206.15
}

Received: March 14, 2017; Accepted: April 10, 2017; Published: December 19, 2017

\begin{abstract}
This study investigated the student's awareness on environmental issues and problems and their behaviors towards the environment in different public and private universities in Bangladesh. In this regards data has been collected from the students of two public universities and two private universities. A sample of 400 students $(60 \%$ male and $40 \%$ female) was drawn from these four Universities taking 100 students from each university and equally sharing the number between two categories like environmental background and non-environmental background. The analysis revealed that according to the perception of the surveyed students global warming $(86.5 \%)$ and depletion of natural resources $(71.2 \%)$ were two most important environmental problems in the world whereas in Bangladesh, arsenic contamination in ground water (93.2\%) and natural resources depletion $(71.2 \%)$ have found as major environmental problems. The study concluded that peoples' education on environment (98\%) is a most convenient solution for mitigating the problems and the printing \& electronic media $(78.8 \%)$ are most helpful means to bring awareness among people.
\end{abstract}

Keywords: Science and Technology, Environmental Education, Social Morals, Climate Change

\section{Introduction}

The environment is of global concern today and is burning issue for discussion. Because the global environment is changing more rapidly than any time in the known history and it is difficult to force all the changes that will occur in the $21^{\text {st }}$ century. The world is now alarmed with various environmental problems, such as climate change, ozone layer depletion, global warming, and so on. Many of these problems are the result of irresponsible environmental behaviour, which is highly influenced by the attitudes people possess [1-2]. In other words, people's decision-making is also guided by the values and attitudes they possess [3]. Environmental attitudes are therefore a big concern in significant environmental education research [4-9]. Bangladesh is also facing many environmental problems because of its rising population and industrial growth. Only individuals who have environmental literacy, awareness, and sensibility would contribute the diminishing the environmental problems. Therefore, environmental education has been viewed as an important way to educate students about environmental issues in identifying and challenging environmental problems in all educational levels including university [10-12]. Particularly Universities and other equivalent institutions play a leading role in promoting of environmental ethics and the principles sustainable development [13]. So right now environmental awareness is a prime concern and that is why environmental education is mandatory in all level of education. The educational process becomes sustainable when the people decide to act, when they take responsibility and lead the process themselves. In this model of development, education and communication are important tools for managers, civil servants, social groups and NGOs to put into effect environmentally sound policies [14]. Until 1995, the coverage of the environment in the higher education system was rather disjointed and poorly developed. In 1996, the environmental science discipline was established at Khulna University, and full session courses (four year undergraduate courses) started in 1997. Recently some public universities like Shahajalal University of Science and Technology, Jahangirnagar University, Chittagong University and Dhaka University etc. have been 
offering undergraduate and graduate course in Environmental Education (EE). At the same time, some private universities like North South University, Independent University Bangladesh, Stamford University Bangladesh and State University Bangladesh have opened EE courses. The study was conducted to investigate the environmental awareness of the students from private and public universities.

\section{Methods}

In this study data has been collected from two public universities (Dhaka University and Jahangirnagar University) and two private universities (Stamford University Bangladesh and State University of Bangladesh). A sample of 400 students ( $60 \%$ male and $40 \%$ female) was drawn from these four Universities taking 100 students from each university and equally sharing the number between two categories like environmental background and nonenvironmental background (Table 1). For collecting data, a structured questionnaire survey was conducted among the participants. The questionnaire was prepared comprising 10 major environmental issues such as General perception on environment, Awareness on environmental pollution (air, soil and noise), Awareness on safe water, Awareness on arsenic pollution, Knowledge on sanitation practice, Awareness on waste management, Awareness on energy use, Awareness on bio-diversity, Global warming and Climate Change. The questionnaires were supplied at the end of class periods or during their gathering in their particular departmental library. Students responded their voluntarily for this survey.

Table 1. Distribution of the study subjects according to their background and university.

\begin{tabular}{|c|c|c|c|}
\hline Background & Name of University & $\mathbf{f}$ & $\%$ \\
\hline \multirow{2}{*}{ Environmental Background } & Dhaka University & 100 & 25.0 \\
\hline & Jahangirnagar University & 100 & 25.0 \\
\hline Non Environmental Background & Stamford University Bangladesh & 100 & 25.0 \\
\hline Total & & 400 & 100.0 \\
\hline
\end{tabular}

\section{Results and Discussion}

Environmental problems (air pollution, water pollution, soil pollution, noise pollution, climate change etc.) are the causes of environmental degradation. Environmental degradation refers to the deterioration in its physical component brought about by human activities to such an extent that it cannot be set right by the self-regulatory mechanism or homeostic mechanism of the environment. While analyzing the clear knowledge on the general perception on Environment it was revealed that the environmental background student has more clear understanding comparing to non environmental background student. From the table 2, it was found that out of 400 respondents $84.8 \%$ has a clear knowledge on different components of environment. The study also shows that, environmental background student has more understanding comparing to non environmental background student. $47.2 \%$ environmental background student has a clear understanding on the issue whereas it was $37.5 \%$ among the non environmental background students.

Table 2. Knowledge on different components of environment.

\begin{tabular}{lllll}
\hline Group & & N & \% of Total N & Std. Deviation \\
\hline \multirow{3}{*}{ Environmental background } & Yes & 189 & 47.2 & .510 \\
& No & 11 & 2.8 & .701 \\
& Total & 200 & 50.0 & .554 \\
\multirow{2}{*}{ Non Environmental Background } & Yes & 150 & 37.5 & .657 \\
& No & 50 & 12.5 & .718 \\
& Total & 200 & 50.0 & .709 \\
Total & Yes & 339 & 84.8 & .581 \\
& No & 61 & 15.2 & .714 \\
\hline
\end{tabular}

Table 3. Major source for causing environmental problems for Bangladesh?

\begin{tabular}{lllll}
\hline Group & & N & \% of Total N & Std. Deviation \\
\hline & OP & 181 & 45.2 & .561 \\
Environmental background & ST & 3 & .8 & .000 \\
& LEE & 14 & 3.5 & .514 \\
& SM & 2 & .5 & .707 \\
& Total & 200 & 50.0 & .554 \\
Non Environmental Background & OP & 161 & 40.2 & .708 \\
& ST & 19 & 4.8 & .697 \\
& LEE & 16 & 4.0 & .727 \\
\hline
\end{tabular}




\begin{tabular}{lllll}
\hline Group & & N & \% of Total N & Std. Deviation \\
\hline \multirow{4}{*}{ Total } & OP & 342 & 85.5 & .640 \\
& ST & 22 & 5.5 & .671 \\
& LEE & 30 & 7.5 & .630 \\
& SM & 6 & 1.5 & .837 \\
& Total & 400 & 100.0 & .643 \\
\hline
\end{tabular}

Note: $\mathrm{OP}=$ Over Population, $\mathrm{ST}=$ Science and Technology Development, LEE=Lack of Environmental Education and SM=Social Morals.

From the table 3, it was found, out of 400 respondents $85.5 \%$ have marked OP as a major source for causing environmental problems for Bangladesh. While analyzing it was revealed that the environmental background student has more understanding comparing to non environmental background student. $45.2 \%$ environmental background has a clear understanding on the issue whereas it was $40.2 \%$ among the non environmental background students.

The respondents were requested to answer on the causes of air pollution (Table 4). The study shows that, $61.5 \%$ have clear knowledge on the causes of air pollution and moderately $33.5 \%$. While analyzing it was revealed that the environmental background student has more understanding comparing to non environmental background student. $39.2 \%$ environmental background has a clear understanding on the issue whereas it was $22.2 \%$ among the non environmental background students.

Table 4. How much you know about the causes of air pollution.

\begin{tabular}{lllll}
\hline Group & & N & \% of Total N & Std. Deviation \\
\hline \multirow{3}{*}{ Environmental background } & Clearly & 157 & 39.2 & .503 \\
& Moderately & 36 & 9.0 & .558 \\
& Fairly & 7 & 1.8 & .900 \\
& Total & 200 & 50.0 & .554 \\
\multirow{3}{*}{ Non Environmental Background } & Clearly & 89 & 22.2 & .699 \\
& Moderately & 98 & 24.5 & .677 \\
& Fairly & 13 & 3.2 & .862 \\
& Total & 200 & 50.0 & .709 \\
Total & Clearly & 246 & 61.5 & .587 \\
& Moderately & 134 & 33.5 & .645 \\
& Fairly & 20 & 5.0 & .852 \\
& Total & 400 & 100.0 & .643 \\
\hline
\end{tabular}

Table 5. Do you know about the causes of water pollution?

\begin{tabular}{lllll}
\hline Group & & N & \% of Total N & Std. Deviation \\
\hline \multirow{2}{*}{ Environmental } & Yes & 190 & 47.5 & .543 \\
background & No & 10 & 2.5 & .699 \\
& Total & 200 & 50.0 & .554 \\
Non Environmental & Yes & 162 & 40.5 & .738 \\
Background & No & 38 & 9.5 & .414 \\
& Total & 200 & 50.0 & .709 \\
\multirow{2}{*}{ Total } & Yes & 352 & 88.0 & .656 \\
& No & 48 & 12.0 & .515 \\
& Total & 400 & 100.0 & .643 \\
\hline
\end{tabular}

Water pollution is a very common scenario in Bangladesh. Respondents were asked to mention whether they know about the causes of water pollution or not. Table 5 showed that, out of 400 respondents $88 \%$ has know about the causes of water pollution. While analyzing it was revealed that the environmental background student has more understanding comparing to non environmental background student. $47.5 \%$ environmental background has a clear understanding on the issue whereas it was $40.5 \%$ among the non environmental background students.

Whenever respondents were asked to mention whether they know about biodiversity degradation, environmental background students found to have more understanding on the issue. From the table 6 it was found, out of 400 respondents $71.2 \%$ has know about biodiversity reduction. While analyzing it was revealed that the environmental background student has more understanding comparing to non environmental background student. $47 \%$ environmental background has a clear understanding on the issue whereas it was $24.2 \%$ among the non environmental background students.

Table 6. Knowledge about biodiversity degradation.

\begin{tabular}{lllll}
\hline Group & & N & \%of Total N & Std. Deviation \\
\hline \multirow{2}{*}{ Environmental } & Yes & 188 & 47.0 & .545 \\
background & No & 12 & 3.0 & .674 \\
& Total & 200 & 50.0 & .554 \\
Non & Yes & 97 & 24.2 & .723 \\
Environmental & No & 103 & 25.8 & .698 \\
Background & Total & 200 & 50.0 & .709 \\
& Yes & 285 & 71.2 & .618 \\
Total & No & 115 & 28.8 & .693 \\
& Total & 400 & 100.0 & .643 \\
\hline
\end{tabular}

Respondents were asked why they consider global warming is a major issue in the perspective of Bangladesh. From the survey (Table 7 ) it was come out that $86.5 \%$ has awareness about the consequence of global warming in general. While analyzing it was revealed that the environmental background student has more understanding comparing to non environmental background student. $49.2 \%$ environmental background has a clear understanding on the issue whereas it was $37.2 \%$ among the non environmental background students. 
Table 7. Are you of the consequence of global warming in general?

\begin{tabular}{lllll}
\hline Group & & N & \% of Total N & Std. Deviation \\
\hline \multirow{2}{*}{ Environmental } & Yes & 197 & 49.2 & .558 \\
background & No & 3 & .8 & .000 \\
Non & Total & 200 & 50.0 & .554 \\
Environmental & Yes & 149 & 37.2 & .692 \\
Background & Total & 51 & 12.8 & .753 \\
& Yes & 346 & 50.0 & .709 \\
Total & No & 54 & 13.5 & .623 \\
& Total & 400 & 100.0 & .744 \\
& & &
\end{tabular}

Respondents pointed out a number of consequences to consider climate change as the main problem. From the table 8 it was found, out of 400 respondents $84 \%$ has aware about the consequence of climate change in Bangladesh. While analyzing it was revealed that the environmental background student has more understanding comparing to non environmental background student.

Table 8. Are you of consequence of climate change in Bangladesh?

\begin{tabular}{lllll}
\hline Group & & $\mathbf{N}$ & \% of Total N & Std. Deviation \\
\hline Environmental & Yes & 197 & 49.2 & .556 \\
background & No & 3 & .8 & .577 \\
& Total & 200 & 50.0 & .554 \\
Non & Yes & 139 & 34.8 & .706 \\
Environmental & No & 61 & 15.2 & .721 \\
Background & Total & 200 & 50.0 & .709 \\
& Yes & 336 & 84.0 & .629 \\
Total & No & 64 & 16.0 & .711 \\
& Total & 400 & 100.0 & .643 \\
\hline
\end{tabular}

During survey, students were asked to respond on the issue of ways for environmental management. Survey showed (Table 9) that respondents have given emphasis on EA $62.5 \%$ for Environmental management depends followed by SI (14.8\%) and LR (8.8\%). While analyzing it was revealed that the environmental background student has more understanding comparing to non environmental background student.

Table 9. Environmental management depends on.

\begin{tabular}{lllll}
\hline Group & & N & \% of Total N & Std. Deviation \\
\hline & LR & 26 & 6.5 & .491 \\
Environmental & IE & 35 & 8.8 & .568 \\
background & SI & 24 & 6.0 & .338 \\
& EA & 115 & 28.8 & .586 \\
& Total & 200 & 50.0 & .554 \\
Non & LR & 9 & 2.2 & .441 \\
Environmental & IE & 21 & 5.2 & .811 \\
Background & SI & 35 & 8.8 & .591 \\
& EA & 135 & 33.8 & .731 \\
& Total & 200 & 50.0 & .709 \\
& LR & 35 & 8.8 & .473 \\
Total & IE & 56 & 14.0 & .690 \\
& SI & 59 & 14.8 & .512 \\
& EA & 250 & 62.5 & .671 \\
& Total & 400 & 100.0 & .643 \\
\hline
\end{tabular}

Note: a) LR=Legal Regulations b) $\mathrm{IE}=$ Individual Efforts c) $\mathrm{SI}=$ State Input d) $\mathrm{EA}=$ Environmental Awareness
Table 10. What are the sources to create environmental awareness?

\begin{tabular}{llll}
\hline Group & Sources & N & \% of Total N \\
\hline & T. V. & 34 & 8.5 \\
Environmental & Radio & 25 & 12.5 \\
background & From elders & 6 & 3 \\
& Book/ newspapers & 135 & 67.5 \\
& Total & 200 & 50.0 \\
& T. V. & 108 & 54 \\
Non Environmental & Radio & 14 & 7 \\
Background & From elders & 10 & 5 \\
& Book/ newspapers & 67 & 33.5 \\
& Total & 200 & 50.0 \\
& T. V. & 142 & 35.5 \\
Total & Radio & 39 & 9.75 \\
& From elders & 16 & 4 \\
& book/ newspapers & 202 & 50.5 \\
& Total & 400 & 100.0 \\
\hline
\end{tabular}

During the survey, respondents were requested to answer the issue of the sources of environmental awareness. Environmental background students emphasized book/newspaper more than non environmental students $(33.5 \%)$ and $\mathrm{TV}$ has come out as the second awareness source $(35.5 \%)$ where non environmental students emphasize it more than environmental back ground students $(8.5 \%)$ as in Table 10. From both background students response, book/newspaper $(50.5 \%)$ has pointed out as the most important source for creating awareness. Radio is in third source of awareness $(9.75 \%)$ where environmental students $(12.5 \%)$ have emphasized it more comparing to non environmental back ground students $(7 \%)$. Elders also play a role to make awareness but it is negligible (4\%).

\section{Conclusions}

From the investigation, it has found that the main key of awareness is education. It starts with primary level and keeps on upgrading by diverse of knowledge through different lessons. Among different education levels, University level Students do gain most advanced and effective lesson through class and research work. That is why they have picked up the most serious problem in the world is global worming (95\%) and the second most serious problem is depletion of natural resources $(71.2 \%)$. And the third marking problem is ozone depletion. In case of Bangladesh the remarking environmental problems are depletion of natural resources, then arsenic contamination in ground water and the last air pollution. In addition majority students focused on unplanned urbanization as an environmental issue in future. This is consistent with the previous literature university students were found at a high level of awareness and sensibility to environmental problems [15-16]. The student's general attitude about the environmental problems that may occur in the future has been assessed as pessimistic. Using of the recycled materials in industries, renewable energy and environmental protection activities are the other possible solutions that came out of the survey. It is also shown that TV, Radios playas the most important role to get the attention of the people to raise the awareness about the environmental 
issues. Moreover printing media including some other publications act as a secondary way of raising awareness among the people to protect environment. Environmental organization and educational institutions should base their activities on the young generations and they should be encouraged to read and learn about the environmental issue in the educational institution.

\section{References}

[1] Meinhold, J. L., \& Malkus, A. J. Adolescent environmental behaviors. Can knowledge, attitudes, and self-efficacy make a difference? Environment and Behavior, 37(4), 2005, 511532.

[2] Ramsey, C. E., \& Rickson, R. E. Environmental knowledge and attitudes. The Journal of Environmental Education, 8(1), 1976, 10-18.

[3] Rennie, L. J. Values in science in out-of-school contexts. In D. Corrigan, J. Dillon \& R. Gunstone (Eds.), The re-emergence of values in science education 2007, (pp. 197-212). Rotterdam: Sense Publishers.

[4] Clarke, B. Environmental attitudes and knowledge of Year 11 students in a Queensland high school: An investigation into environmental beliefs and understandings. Australian Journal of Environmental Education, 12, 1996, 19-26.

[5] Ridener, L. R. University students' attitude to the environment: An Australian/ USA comparison and the effects of an educational program. Australian Journal of Environmental Education, 13, 1997, 77-84.

[6] Bradley, J. C., Waliczek, T. M., \& Zajicek, J. M. Relationship between environmental knowledge and environmental attitude of high school students. The Journal of Environmental Education, 30(3), 1999, 17-21.

[7] Eagles, P. F. J., \& Demare, R. Factors influencing children's environmental attitudes. The Journal of Environmental Education, 30(4), 1999. 33-37.
[8] DiEnno, C. M., \& Hilton, S. C. High school students' knowledge, attitudes, and levels of enjoyment of an environmental education unit on nonnative plants. The Journal of Environmental Education, 37(1), 2005, 13-25.

[9] Lee, E. B. Environmental attitudes and information sources among African American college students. The Journal of Environmental Education, 40(1), 2008, 29-42.

[10] Fernández-Manzanal, R., Rodríguez-Barreiro, L., \& Carrasquer, J. Evaluation of environmental attitudes: analysis and results of a scale applied to university students. Science Education, 91(6), 2007, 988-1009.

[11] Tuncer, G., Tekkaya, C., Sungur, S., Çakiroglu, J., Ertepinar, H., \& Kaplowitz, M. Assessing pre-service teachers' environmental literacy in Turkey as a mean to develop teacher education programs. International Journal of Educational Development, 29, 2009, 426-436.

[12] Uzun, N., \& Saglam, N. Environmental attitude scale for high school students. Journal of Hacettepe Education Faculty, 30, 2006, 240-250.

[13] Delakowitz, B. and Hoffmann, A. The Hochschule Zittau/Görlitz Germany's first registered environmental management (EMAS) at an institution of higher education. International Journal of Sustainability in Higher Education, vol 1, issue 1. Technical University, Hamburg-Harburg, Germany,2000.

[14] Van Hemert, M., Wiertsema, Wiert \& van Yperen, Michael. Reviving Links-NGO Experiences in Environmental Education and People's Participation in Environmental Policies, Both Ends/SME Milieu Adviseurs/IUCN, 1995.

[15] Kahraman, S., Yalçin., M., Özkan, E., \& Aggül, F. Prospective elementary school teachers' aware of global warming and levels of knowledge. Journal of Gazi Education Faculty, 28(3), 2008, 249-263.

[16] Özdemir, O., Yildiz, A., Ocaktan, E., \& Sarisen, Ö. Medical student' aware and sensitiveness about environmental problems. Ankara University, Medicine Faculty Bulletin, 57(3), 2004, 117-127. 